\title{
Prebiotics in Management of Neonatal Jaundice: Open Label Randomised Control Trial
}

\author{
Trupti Amol Joshi', Amol Kalyanrao Joshi², Laxmikant Sheshrao Deshmukh ${ }^{3}$ \\ ${ }^{1}$ Associate Professor, Department of Paediatrics, Government Medical College Aurangabad, Maharashtra, India, ${ }^{2}$ Fellowship Neonatology, Associate Professor, Department \\ of Neonatology, Government Medical College Aurangabad, Maharashtra, India, ${ }^{3}$ Professor, Department of Neonatology, Government Medical College Aurangabad, \\ Maharashtra, India.
}

\section{Abstract}

Background: Approximately 5-35\% of neonates develop jaundice requiring treatment during the 1st week of life. Prebiotics, a mixture of Galacto-oligosaccharides (GOS) and Fructo-oligosaccharides (FOS), has been postulated to reduce serum bilirubin levels on principle of interruption of entero-hepatic circulation. Objective: To evaluate the effect of oral supplementation with prebiotics (Fructo-oligosaccharides) in the management of neonatal jaundice. Subjects and Methods: Design \& Setting: Open Label, Randomized Control Trial at Level II NICU in public hospital over one year. Participants: Term exclusively breast-fed neonates with Jaundice requiring phototherapy. Intervention: Randomisation of Sixty eligible neonates into Control and Prebiotic groups ( $\mathrm{n}=30$ each). Both groups received phototherapy, and Prebiotic group received additional oral prebiotics. Outcome: Primary outcome measure was a reduction in total serum bilirubin levels (TSB) and duration of phototherapy. The secondary outcome measure was the change in the frequency of stools. Results: Baseline Features were similar in both groups. Overall serum bilirubin levels decreased significantly from enrolment till the omission of phototherapy (17.24 +1.16 vs. 12.74 +0.48 ; P: 0.00). ANOVA depicted no statistical difference between the groups in 12 hourly reductions of TSB (F [3, 232] = 0.14, P: 0.94). Mean duration of phototherapy (in hours) required in prebiotic and control group was similar $(50.40+9.66$ vs. $47.60+8.62 ; \mathrm{P}=0.24)$. Secondary outcome measures were also similar in both groups. Conclusion: Prebiotics, containing only fructo-oligosaccharides, administered for upto three days, do not have any additional effect on reduction of serum bilirubin levels in neonates with jaundice receiving conventional treatment.

Keywords: Inulin, Oligo-saccharides, Phototherapy, Bilirubin.

Corresponding Author: Dr. Amol Kalyanrao Joshi, 15 A "SNEHKAMAL," Siddhesh Nagar, Shreya Nagar (South), Behind Pawan Gas Godown, Aurangabad 431005, Maharashtra, India

Received: November 2019

Accepted: November 2019

\section{Introduction}

Approximately $60 \%$ of term neonates develop jaundice during the first week of life. ${ }^{[1]}$ It occurs due to physiological transition process resulting from increased bilirubin production (due to breakdown of red blood cells), its defective uptake and decreased clearance by the immature liver. In term neonates, total serum bilirubin level usually rises to a peak of $6-8 \mathrm{mg} / \mathrm{dl}$ by 3 to 5 days of age and then falls. Levels $<2 \mathrm{mg} / \mathrm{dL}$ may not be seen until 1 month of age. ${ }^{[2]}$

Severe neonatal jaundice, defined as total serum bilirubin (TSB) above the 95th percentile for age on the hour specific nomogram, is seen in 5 to $35 \%$ of neonates. ${ }^{[3-5]}$ It can lead to substantial morbidity and mortality. ${ }^{[6]}$ Therefore; its proper and timely treatment is of critical importance. Phototherapy is the mainstay of management of neonatal jaundice. ${ }^{[7]}$

Phototherapy does not cause serious side effects, but recently it has been observed in some clinical trials on neonates that phototherapy (both conventional and intensive types) is associated with DNA damage.${ }^{[8,9]}$ Clinical trials on various add on pharmacological therapies for reducing the requirement of phototherapy with insufficient evidence for their use in clinical practice. ${ }^{[10-12]}$

Use of Prebiotics is a promising and novel strategy in the management of neonatal jaundice. Prebiotics are "nondigestible food components that affect the host beneficially by selectively stimulating the growth and/ or activity of one or a limited number of bacteria in the colon, thereby improving host health" ${ }^{[13]}$ Oral administration of specific mixture of short-chain galacto-oligosaccharides (GOS) and long-chain fructo-oligosaccharides (FOS) in 9:1 ratio in the dosage of $0.4-0.8$ grams $/ 100 \mathrm{ml}$ of enteral milk has a proven benefit in the development of early microbiota, increased stool frequency and stool softness. ${ }^{[14,15]}$

The hypothesis suggests that enteral supplementation of prebiotics leads to decrease in bilirubin levels by reducing entero-hepatic circulation (by mechanism of reducing conversion of conjugated bilirubin to unconjugated bilirubin). Few Randomised control Trials have shown benefits of enteral administration of Prebiotics (GOS \& FOS 
mixture) in prevention and management of jaundice in neonates. ${ }^{[16-18]}$ Studies in neonates on Prebiotics preparation containing only FOS are also available. ${ }^{[19]}$

FOS supplement is available in India and not GOS \& FOS mixture. Hence, this study was conducted to evaluate the effect of FOS (Inulin) on TSB in term neonates with jaundice.

\section{Subjects and Methods}

\section{Trial Design:}

It was an Open-Label, Randomized, Control Trial conducted at level II NICU in public hospital over one year. The institutional ethics committee approved the trial.

\section{Participants:}

All term neonates admitted with Jaundice requiring phototherapy were assessed for eligibility by a neonatologist. Exclusion criteria were Newborn with birth weight $<2500$ grams, Formula fed, those requiring exchange transfusion, sick neonates (with hypotension, temperature instability, acidosis, sepsis, dehydration) and Congenital GIT malformations. Parental Informed Consent before enrollment.

\section{Sample size:}

The Sample size was calculated as total 60 (30 in each group) considering $80 \%$ power and Type 1 error of $5 \%$. Calculations were based on an expected effect size of at least $0.8 \mathrm{mg} / \mathrm{dl}$ TSB as observed in a previous Randomized Control Trial, ${ }^{[17]}$ with an estimated $10 \%$ drop-out rate.

\section{Randomization sequence generation:}

Block randomization was done using a web-based random number generator using permuted blocks of two. Randomization of the enrolled patients into two groups (Prebiotic group and Control group). Allocation concealment was done using sequentially numbered, opaque, sealed envelopes. Blinding was not intended in this study.

\section{Interventions:}

Total Serum Bilirubin (TSB) documentation on age-specific bilirubin nomogram at enrolment. Both the groups received Phototherapy (Single surface, LED Phototherapy with Spectral Irradiance: 20 microwatt $\mathrm{cm}^{-2} \mathrm{~nm}^{1}$ at $30 \mathrm{~cm}$ from the light unit). Prebiotic Group received additional supplement of long-chain fructo-oligosaccharide FOS (inulin) in powder form, administered at a dosage of 1.5 grams/kg/day divided into three doses. ${ }^{[18]}$ Each part of the preparation was dissolved in $10 \mathrm{ml}$ of mother's own expressed breast milk and was administered three times a day using cup \& spoon. Babies immediately breastfed after prebiotic administration. The endpoint was the omission of phototherapy according to age-specific bilirubin nomogram.

\section{Data collection:}

Demographic data was collected. Serial TSB was recorded at enrollment and 12 hourly till the endpoint. Frequency of stools was documented at registration and then at an interval of 24 hours till endpoint. Side effects if any documented. Epi-info software version 7.2 was used to facilitate data collection.

\section{Outcomes:}

The primary outcome measure was the reduction in serum bilirubin levels and the required duration of phototherapy. Change in frequency of stools was the secondary outcome measure.

\section{Statistical methods:}

Statistical analysis was done using Microsoft excel 2010 (Microsoft Corporation, NY, USA) and SPSS (Statistical Package for the Social science Inc. Chicago, IL, USA) VERSION 19. 0. Continuous variables presented as mean \& standard deviation. Chi-Square test was for applied for qualitative variables. The continuous data compared between the groups using unpaired Students t-test for normally distributed data and Mann -Whitney $U$ test for skewed data. Continuous variables with multiple measures obtained over time were analyzed using ANOVA for between-group differences. P-Value of $\leq 0.05$ was considered statistically significant.

\section{Results}

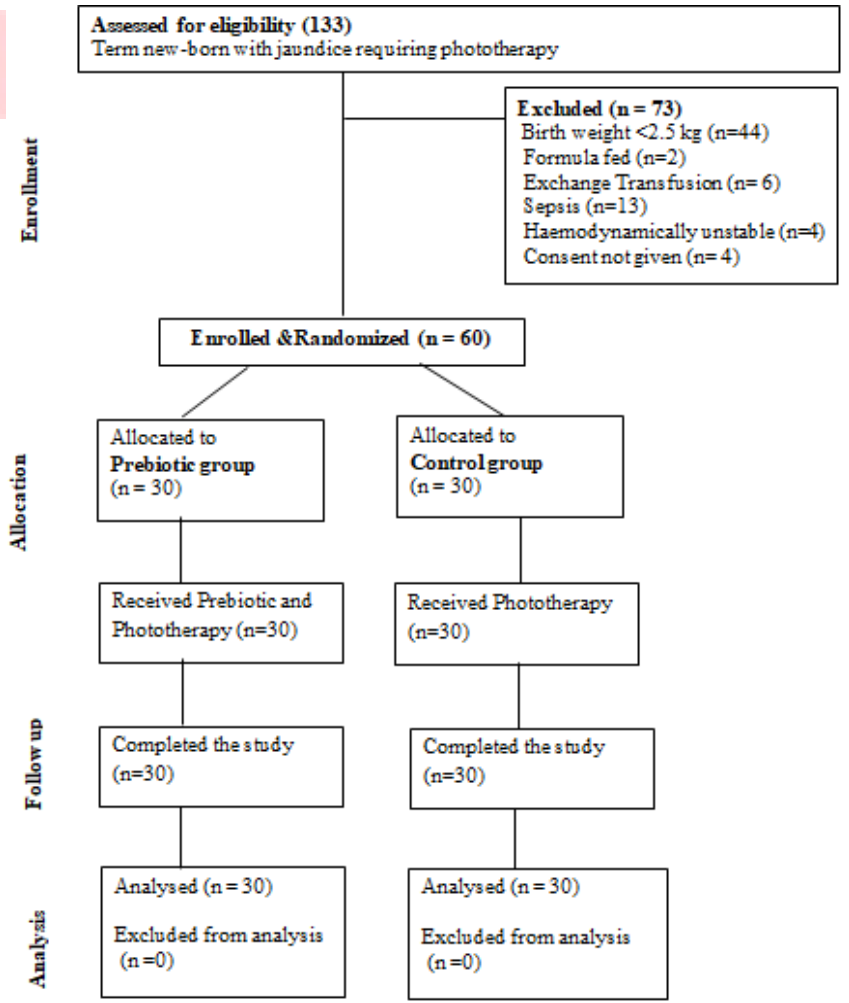

Figure 1: Patient flow diagram 
Table 1: Baseline characteristics

\begin{tabular}{|c|c|c|c|c|c|}
\hline \multirow{2}{*}{$\begin{array}{l}\text { Characteristics } \\
\text { Continuous } \\
\text { variables } \\
\text { At enrolment }\end{array}$} & \multicolumn{2}{|c|}{$\begin{array}{l}\text { Prebiotic } \\
(\mathbf{n}=30)\end{array}$} & \multicolumn{2}{|c|}{$\begin{array}{l}\text { Control group } \\
(\mathbf{n}=30)\end{array}$} & \multirow[t]{2}{*}{$\begin{array}{l}\text { P- } \\
\text { Value }\end{array}$} \\
\hline & Mean & SD & Mean & SD & \\
\hline Weight (grams) & 2827 & 238 & 2843 & 233 & $0.78^{*}$ \\
\hline Age (Hours) & 57 & 14 & 58 & 18 & $0.78^{*}$ \\
\hline TSB $(\mathrm{mg} / \mathrm{dl})$ & 17.03 & 1.34 & 16.77 & 1.58 & $0.14^{*}$ \\
\hline Stool frequency & $\begin{array}{l}\text { Median } 4 \\
\text { Max.8) }\end{array}$ & (Min. 3, & $\begin{array}{l}\text { Median } 5 \\
\text { Max.7) }\end{array}$ & (Min. 2, & $0.47 \#$ \\
\hline \multicolumn{6}{|c|}{ Dichotomous variables } \\
\hline \multirow[t]{2}{*}{ Gender } & Male & Female & Male & Female & \multirow[t]{2}{*}{$0.80 \$$} \\
\hline & 14 & 16 & 13 & 17 & \\
\hline \multirow[t]{2}{*}{ Mode of delivery } & Vaginal & LSCS & Vaginal & LSCS & \multirow[t]{2}{*}{$1 \$$} \\
\hline & 17 & 12 & 17 & 12 & \\
\hline \multicolumn{6}{|c|}{ Risk factors for jaundice } \\
\hline $\begin{array}{l}\text { ABO } \\
\text { Incompatibility }\end{array}$ & \multicolumn{2}{|l|}{15} & \multicolumn{2}{|l|}{17} & \multirow[t]{3}{*}{$0.77 \$$} \\
\hline Birth asphyxia & \multicolumn{2}{|l|}{02} & \multicolumn{2}{|l|}{01} & \\
\hline Maternal oxytocin & \multicolumn{2}{|l|}{09} & \multicolumn{2}{|l|}{08} & \\
\hline
\end{tabular}

Total 133 neonates with jaundice requiring phototherapy admitted over one year. After excluding seventy-three neonates, sixty randomized into Prebiotic group and Control group ( $n=30$ each). All neonates completed the study and included in analysis. [Figure 1]

The mean age of presentation of enrolled neonates was $58+$ 16 hours of life. The average weight of the enrolled neonates was $2835+233$ grams. There were 27 (45\%) male and
$33(55 \%)$ female new-borns. Baseline data were comparable in both the groups. [Table 1]

Change in serum bilirubin levels: The mean total reduction in TSB at the endpoint was similar in both Prebiotic and Control groups [Table 2]. Overall serum bilirubin levels decreased significantly from enrolment till the omission of phototherapy $(17.24+1.16$ vs. $12.74+0.48$; mean difference 4.5 ; $95 \%$ Confidence interval [CI] 4.17, 4.82; P: 0.00). Serum bilirubin levels decreased significantly in both the Prebiotic (from $17.42+0.80$ to $12.77+0.48$; mean difference $4.47 ; 95 \% \mathrm{CI} 4.12,4.81 ; \mathrm{P}=0.00)$ and control (from $17.07+1.43$ to $12.72+0.48$; mean difference 4.35 ; $95 \%$ CI 3.80, 4.90; $\mathrm{P}=0.00)$ groups. At end of intervention, the serum bilirubin levels were similar between the groups $(12.77+0.48$ vs. $12.72+0.48$; mean difference $0.05 ; 95 \%$ [CI] $-0.20,0.30 ; \mathrm{P}=0.68)$. TWO WAY ANOVA with repeated measures analysis depicted, that the difference in 12 hourly reductions of TSB amongst Prebiotic and Control group was not statistically significant $(\mathrm{F}[5,348]=0.27, \mathrm{P}$ : 0.93). [Figure 2]

Duration of phototherapy: Mean duration of phototherapy in prebiotic and control group was similar $(50.40+9.66$ vs. $47.60+8.62$; mean difference $2.8 ; 95 \%[\mathrm{CI}]-1.932,7.532$; $\mathrm{P}=0.24)$. [Table 2]

Frequency of stools: There was no significant difference in frequency of stools at 24 hours and 48 [Figure 3].

Side effects: Side effects of prebiotics not observed.

Table No. 2: Observed Outcome measures in the study groups

\begin{tabular}{|c|c|c|c|c|c|c|c|}
\hline Parameter & \multicolumn{2}{|c|}{ Prebiotic group $(n=30)$} & \multicolumn{2}{|c|}{ Control group $(n=30)$} & \multirow{2}{*}{ Mean difference } & \multirow[t]{2}{*}{$95 \% \mathrm{CI}$} & \multirow[t]{2}{*}{ P-VALUE* } \\
\hline & Mean & SD & Mean & SD & & & \\
\hline $\begin{array}{l}\text { Mean Serum Bilirubin at } \\
\text { the endpoint }(\mathrm{mg} / \mathrm{dl})\end{array}$ & 12.77 & 0.48 & 12.72 & 0.48 & 0.05 & $-0.20,0.30$ & .68 \\
\hline $\begin{array}{l}\text { Mean Total reduction in } \\
\text { serum bilirubin }(\mathrm{mg} / \mathrm{dl})\end{array}$ & 4.65 & 0.80 & 4.35 & 1.36 & 0.3 & $-0.28,0.88$ & 0.30 \\
\hline $\begin{array}{lr}\text { Mean duration } & \text { of } \\
\text { Phototherapy required } \\
\text { (hours) }\end{array}$ & 50.40 & 9.66 & 47.60 & 8.62 & 2.8 & $-1.93,7.53$ & 0.24 \\
\hline
\end{tabular}

SD: Standard Deviation, CI: Confidence Interval, * Unpaired Student T Test

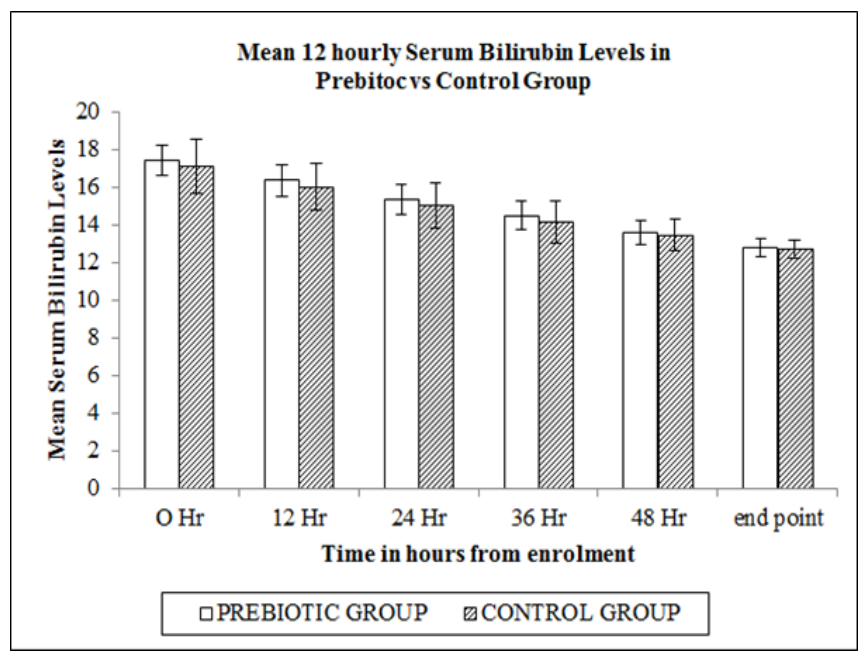

Figure 2: Mean serum bilirubin levels from enrolment until the end of intervention

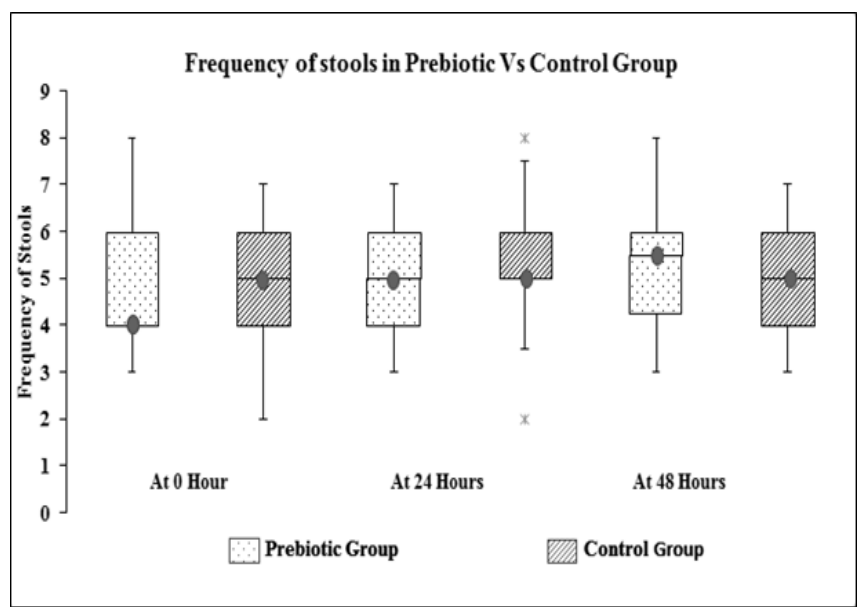

Figure 3: Box Plot showing Frequency of stools in Prebiotic VS Control Group from enrolment until the end of the intervention 


\section{Discussion}

\section{ESPGHAN (European Society for Paediatric} Gastroenterology, Hepatology, and Nutrition) committee recommends the addition of prebiotics to formula milk. ${ }^{[20]}$ Recommended prebiotics are short-chain galactooligosaccharide (GOS) and long-chain fructooligosaccharides (FOS) in 9:1 ratio. Bisceglia $\mathrm{M}$ et al. ${ }^{[17]}$ used GOS - FOS supplemented milk formula in term neonates over 28 days, and reported it to be safe \& effective in management of mild jaundice in new-borns. Armanian A. $\mathrm{M}$ et al. ${ }^{[18]}$ also reported beneficial effects of GOS - FOS preparation added to the expressed breast milk in preterm neonates. Authors of both these trials attributed this beneficial effect of prebiotics to interruption of enterohepatic circulation due to increased gastrointestinal motility. They documented significant increase in frequency of stools in participants. This effect is also associated with reduced stool viscosity and facilitated growth of Bifidobacterium and Lactobacilli. ${ }^{[13]}$ Dose and duration-dependent accelerated gastrointestinal transit time reported with GOS - FOS use for more than two weeks. ${ }^{[1,22]}$ Euler AR et al. ${ }^{[19]}$ reported increase in stool frequency with high dose FOS supplemented for seven days. In our study also, FOS - only preparation was used, and such beneficial effect was not demonstrated, probably due to shorter duration of FOS administration (2-3 days).

There is limited evidence to suggest the benefit of Prebiotics through facilitated growth of intestinal microflora capable of reducing bilirubin to urobilinoids and its elimination in stool. ${ }^{[23-25]}$

Limitations of the study include GOS \& FOS mixture 9:1 not used, optimal dose and duration not defined, exclusion of pre-terms, stools not evaluated for viscosity and microflora.

Further research recommended, after fulfilling these limitations.

\section{Conclusion}

Supplementation of Prebiotics, containing only fructooligosaccharides for upto three days, does not have any additional effect on reduction of serum bilirubin levels in neonates with jaundice receiving conventional treatment.

\section{'What is Already Known?'}

Prebiotic supplemented formula milk containing mixture of short-chain galacto-oligosaccharides and long-chain fructooligosaccharides in 9:1 ratio shows enhanced gastrointestinal motility and lowers bilirubin levels in neonates with jaundice.

\section{'What this Study Adds.'}

Prebiotics supplementation with only Fructooligosaccharides at a dose of $1.5 \mathrm{gram} / \mathrm{kg} / \mathrm{day}$ for shorter duration does not show any change in gastrointestinal motility or bilirubin levels in neonates with Jaundice.

\section{References}

1. Namasivayam A, Waldemar AC. Jaundice and Hyperbilirubinemia in the Newborn. Richard E. Behrman (ed). Nelson Textbook of Pediatrics volume II, 20th ed. Philadelphia: Elsevier; 2016. Pp. 1175-1180.

2. Ann RS, Vinod KB. Neonatal Hyperbilirubinemia. Eric C. Eichenwald, Anne R. Hansen, Camilia R. Martin, Ann R. Stark (ed). Cloherty and Starks Manual of Neonatal Care, 8th ed. Philadelphia: Wolters Kluwer; 2016. Pp. 299-307

3. Agarwal R, Deorari AK. Unconjugated hyperbilirubinemia in newborns: a current perspective. Indian pediatrics. 2002 Jan;39(1):3042.

4. Narang A, Gathwala G, Kumar P. Neonatal jaundice: an analysis of 551 cases. Indian pediatrics. 1997 May; 34:429-32.

5. Slusher TM, Zamora TG, Appiah D, Stanke JU, Strand MA, Lee BW, Richardson SB, Keating EM, Siddappa AM, Olusanya BO. The burden of severe neonatal jaundice: a systematic review and meta-analysis. BMJ pediatrics open. 2017; 1(1).

6. Mir SE, van der Geest BA, Been JV. Management of neonatal jaundice in low-and lower-middle-income countries.

7. American Academy of Pediatrics. Subcommittee on Hyperbilirubinemia. Management of hyperbilirubinemia in the newborn infant 35 or more weeks of gestation. Pediatrics. 2004; 114:297-316.

8. Ramy N, Ghany EA, Alsharany W, Nada A, Darwish RK, Rabie WA, Aly H. Jaundice, phototherapy and DNA damage in full-term neonates. Journal of Perinatology. 2016 Feb;36(2):132.

9. Yahia S, Shabaan AE, Gouida M, El-Ghanam D, Eldegla H, El-Bakary A, Abdel-Hady H. Influence of hyperbilirubinemia and phototherapy on markers of genotoxicity and apoptosis in full-term infants. European journal of pediatrics. 2015 Apr 1;174(4):459-64.

10. Suresh G, Martin CL, Soll R. Metalloporphyrins for treatment of unconjugated hyperbilirubinemia in neonates. Cochrane Database of Systematic Reviews. 2003(1).

11. Gholitabar M, McGuire H, Rennie J, Manning D, Lai R. Clofibrate in combination with phototherapy for unconjugated neonatal hyperbilirubinemia. Cochrane Database of Systematic Reviews. 2012(12).

12. Mishra S, Cheema A, Agarwal R, Deorari A, Paul V. Oral zinc for the prevention of hyperbilirubinemia in neonates. Cochrane Database of Systematic Reviews. 2015(7).

13. Sherman PM, Cabana M, Gibson GR, Koletzko BV, Neu J, VeeremanWauters G, Ziegler EE, Walker WA. Potential roles and clinical utility of prebiotics in newborns, infants, and children: proceedings from a global prebiotic summit meeting, New York City, June 27-28, 2008. The Journal of pediatrics. 2009 Nov 1;155(5):S61-70.

14. Veereman G. Pediatric applications of inulin and oligofructose. The Journal of nutrition. 2007 Nov 1;137(11):2585S-9S.

15. Vandenplas Y, Greef ED, Veereman G. Prebiotics in infant formula. Gut microbes. 2014 Nov 2;5(6):681-7.

16. Armanian AM, Jahanfar S, Feizi A, Molaeinezhad M, Salehimehr N, Sadeghi E. Prebiotics for the prevention of hyperbilirubinemia in neonates. Cochrane Database of Systematic Reviews. 2017(7).

17. Bisceglia M, Indrio F, Riezzo G, Poerio V, Corapi U, Raimondi F. The effect of prebiotics in the management of neonatal hyperbilirubinemia. Acta paediatrica. 2009 Oct;98(10):1579-81.

18. Armanian AM, Barekatain B, Hoseinzadeh M, Salehimehr N Prebiotics for the management of hyperbilirubinemia in preterm neonates. The Journal of Maternal-Fetal \& Neonatal Medicine. 2016 Sep 16;29(18):3009-13.

19. Euler AR, Mitchell DK, Kline R, Pickering LK. Prebiotic effect of fructo-oligosaccharide supplemented term infant formula at two concentrations compared with unsupplemented formula and human milk. Journal of pediatric gastroenterology and nutrition. $2005 \mathrm{Feb}$ $1 ; 40(2): 157-64$ 
20. Braegger C, Chmielewska A, Decsi T, Kolacek S, Mihatsch W, Moreno L, Piescik M, Puntis J, Shamir R, Szajewska H, Turck D. Supplementation of infant formula with probiotics and/or prebiotics: a systematic review and comment by the ESPGHAN committee on nutrition. Journal of pediatric gastroenterology and nutrition. $2011 \mathrm{Feb}$ 1;52(2):238-50.

21. Moro G, Minoli I, Mosca M, Fanaro S, Jelinek J, Stahl B, Boehm G. Dosage-related bifidogenic effects of galacto-and fructooligosaccharides in formula-fed term infants. Journal of pediatric gastroenterology and nutrition. 2002 Mar 1;34(3):291-5.

22. Scholtens PA, Goossens DA, Staiano A. Stool characteristics of infants receiving short-chain galacto-oligosaccharides and long-chain fructooligosaccharides: a review. World Journal of Gastroenterology: WJG.
2014 Oct 7;20(37):13446.

23. Vítek L, Kotal P, Jirsa M, Malina J, Cerná M, Chmelar D, Fevery J. Intestinal colonization leading to fecal urobilinoid excretion may play a role in the pathogenesis of neonatal jaundice. Journal of pediatric gastroenterology and nutrition. 2000 Mar 1;30(3):294-8.

24. Hamoud AR, Weaver L, Stec DE, Hinds Jr TD. Bilirubin in the livergut signaling axis. Trends in Endocrinology \& Metabolism. 2018 Mar 1;29(3):140-50.

25. Chen Z, Zhang L, Zeng L, Yang X, Jiang L, Gui G, Zhang Z. Probiotics supplementation therapy for pathological neonatal jaundice: a systematic review and meta-analysis. Frontiers in pharmacology. 2017 Jun 30; 8:432.

Copyright: (C) the author(s), 2019. It is an open-access article distributed under the terms of the Creative Commons Attribution License (CC BY 4.0), which permits authors to retain ownership of the copyright for their content, and allow anyone to download, reuse, reprint, modify, distribute and/or copy the content as long as the original authors and source are cited.

How to cite this article: Joshi TA, Joshi AK, Deshmukh LS. Prebiotics in Management of Neonatal Jaundice: Open Label Randomised Control Trial. Asian J. Clin. Pediatr. Neonatol.2019;7(4):17-21.

DOI: dx.doi.org/10.21276/ajcpn.2019.7.4.4

Source of Support: Nil, Conflict of Interest: None declared.
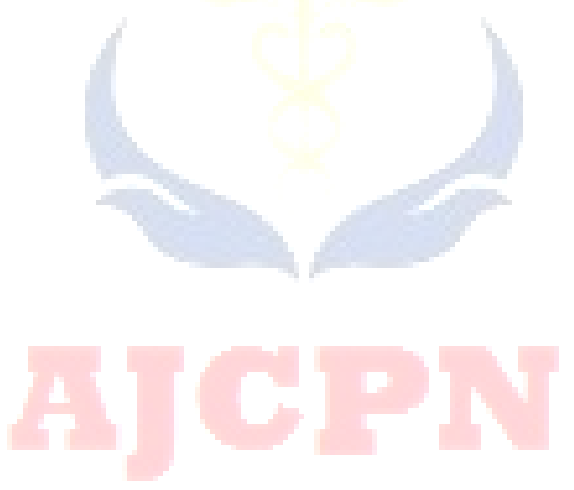